exercise, and want of surface stimulation - in other words, bad housing conditions-also play important parts, and conduce to that condition of relative overfeeding which I have insisted on as the essential element in leading to acidosis. Among the well-to do classes overfeeding and under-exercise are the dual causes.

The treatment of rickets naturally resolves itself into prophylactic and remedial measures. Prophylaxis is concerned with the avoidance of those malhygienic conditions which favour the development of the various forms of malnutrition which have already been described. Correct dieting is essential to avoid catarrhal conditions of the bowel, intestinal toxaemias, and insufficiency diseases, all of which by their respective routes lead to the common goal-acidosis. Food in excess, even though otherwise beyond criticism, is as dangerous as unsuitable food itself, for in the long run it necessitates a short-circuiting of the metabolic processes and the production of acids of large molecular size, such as uric, oxalic, butyric, lactic, propionic, and to some extent of such powerful acids as sulphuric and phosphoric, all of which must be neutralized at the expense of ammonium and other altali reserves of the blood including calcium. Any condition which interferes with oxidation will similarly restrict the completeness of the metabolic processes, and anong them must be included want of fresh air, mechanical obstruction of the respiratory passages by adenoids, embarrassments of the respiratory movements, as well as all other conditions which lead to anoxaemia. Want of stimulation of the skin surface by cool air, good ventilation, or baths, will similarly restrict the oxidation processes.

Want of exercise-as, for instance, by the limitation of muscular activities, such as those concerned in playing, kicking, rolling, and walking-will also predispose to the same results; in fact muscular exercise is the grand prophylactic against rickets. Unfortunately, in the majority of cases of malnutrition which terminate in rickets, active exercise is limited owing to nervous depression, nuclear degenerations, and muscular debility, but none the less every opportunity to ensure free exercise must be provided for all healthy infants. No matter how correctly fed, or how good the other hygienic conditions, infants who are swaddled up in tight clothing so that the movement of the limbs is restricted invariably become rickety, unless the diet is correspondingly reduced.

The avoidance of infections, catarrhal and otherwise, is an essential element in prophylactic treatment, but more easily enjoined than carried out. In healthy, well-fed infants, infections, though they inevitably occur, soon run their course, and it must be remembered that it is chronic and not short-lived acute attacks that lead to the chronic conditions of acidosis which deprive growing bones of their mineral elements.

As for remedial treatment, this depends largely on the correct diagnosis of the cause of the acidosis, on the treatment of the acidosis itself, and on the management of the complications arising from the softening of bone and of the emergencies which are secondary to the acidosis.

The more common causes of the acidosis of rickets have been already indicated, and it is unnecessary to describe in detail the specific measures called for in each particular case. The treatment of the acidosis is by no means a simple task, especially in severe cases with air-hunger, Cheyne-Stokes breathing, tetany, laryngismus stridulus, or convulsions. There are, however, certain important indications, which are as follows:

1. To restore the reduced alkali reserves of the blood.

2. To ensure a free supply of oxygen, and relieve the embarrassment of the respiratory centres.

3. To raise the blood pressure.

4. To promote the excretory functions of the kidneys.

5. To suspend temporarily the intake of food.

6. To restore muscular tone by massage and shower baths.

These, with the exception of No.6, are the measures which have: been empirically proved to be efficacious in such extreme cases of acute acidosis as accur in cholera infantum, diabetic coma, and uraemic conditions.

The reduced alkali reserves and the fall in blood pres sure can both be relieved by the intravenous or subcutaneous injeetion of isotonic saline, or, better, by a 5 per cent. solution of sodium bicarbonate and sodium citrate. Oxygen ean be supplied by inhalations, best by Haldane's continuous method (see British Medical Journal, July 19th, 1919, p. 70).

The excretory functions of the kidneys can be promoted by such cardiac stimulants as camplior, digitalis, strychnine, alcohol, caffeine, etc., or by such direct stimulants as scoparium and turpentine.

The treatment of deformities and mechanical disabilities due to softness of bone need not here be considered beyond referring to the uselessness of splints for the correcicicn of deformities of the legs, if these splints interfere with the one grand prophylactic-namely, the taking of exercise.

The treatment of emergencies, such as laryngismus stridulus, convulsions, and tetany, is as a rule satisfactory and immediate, if conducted on rational lines directed to counteract the effects of a severe acidosis.

In all cases of rickets in which the nervous symptoms are prominent I have found that phosphorated cod-liver oil ( 1 in 10,000) affords most excellent results. The phosphorus may help to restore degenerated nerve cells. I cannot, however, regard it as a general specific for all forms of rickets, as has been claimed by certain German authorities.

In conclusion, I would once again emphasize that all varieties of malnutrition, from whatsoever causes arising, in infants ultimately lead to a condition of acidosis and the characteristic bony changes. Each variety has its own etiology and requires a special line of treatment.

REFERENCE.
John Howland, Johns Hopkins Hosp. Bull., October, 1918, p. 233.

\section{RAT DESTRUCTION}

$$
\text { BY }
$$

F. NORMAN WHITE, M.D., C.I.E.,

MAJOR I.M.S., LATELX SANITARY COMMIBgIONER WITH THE GOVERNMENT IN INDIA.

IN view of the interest now being taken in England in the subject of rat destruction I have been asked to place or record some of the results of Indian experience, mor especially as regards rat poisoning. It is almost unneces sary to remind the reader that the "rat problem" has been for many year :, and is, a problem of the highest publi health importance in India; bubonic plague, so essentiall a rat disease, has been responsible for upwards of ten anc a half million deaths singe the invasion of India by plagu in 1896.

Though Indian experience may well be of assistance te those undertaking rat campaigns in England, it must not be forgotten that in India our greatest efforts have to be directed against the black rat, Rattus rattus, whereas in England the brown rat, Rattus norvegicus, is responsible for most of the damage done. The habits of the two species present striking differences. Rattus rattus, formerly the common rat of England, is now rarely seen outside our ports and large towns; its disappearance is generally ascribed to the advent of $R$. norvegicus. It would seem probable, however, that changes in the customs and habits of the people have had quite as much, if not more, to do with the elimination of $R$. rattus; both species flourish exceedingly in certain eastern cities such as Bombay, where there does not appear to be any marked antagonism between the two species. Their haunts differ it is true, but they have their common meeting places.

This short article deals chiofly with rat destruction by means of poison. It must not be concluded that this, or all the means of destruction put together, is the most important measure that can be adopted in our efforts directed to the elimination of the rat. The protection of foodstuffs from the depredations of rats; efficient scavenging; the proper construction of warehouses, stores markets, shops, granaries, dwelling houses, etc. - all such measures are likely to prove of more permanent benefit and even cheaper in the long run. A direct attack on the rat involves a constant struggle against the remarkable fecundity characteristic of all species of the genus. As a temporary measure, however, rat destruction may be an imperative necessity, notably in the event of a threatened outbreak of a rat-borne disease.

Many well-intentioned and energetieally-prosecuted rat campaigps in India and doubtless in this country also, have yielded disappointing results owing to too little 
attention having been paid to the habits and customs of the particular variety of rat against which war was being waged. This is a matter of very considerable importance. As in so many other matters, chief reliance has been placed in traditional methods, which are by no means always the most efficient. It is commonly stated, for instance, that rats are omnivorous and thrive best on a varied diet. Some go so far as to advocate that the baits of traps and the vehicle for poisons should consist of substances not readily obtainable by the rat. It is true that rats will eat almost anything if driven by hunger to do so; they will become cannibalistio in captivity if deprived of water; but $R$. rattus, at any rate, is for choice almost incredibly conservative in its diet, dislikes variety, and is a strict vegetarian. As a result of some most in. teresting observations carried out in Poona by Dr. Chitre, in an investigation started by Major Kunhardt, I.M.S., it was shown that rats from various parts of India exhibited a marked preference for the food grain, or dough made from the food grain, which formed the staple food of the human population of their place of origin. In comparison with this all other foodstuffs were comparatively unattractive. Moreover, the rats displayed an astonishing aptitude for detecting dough made from the grain to which it had been accustomed, when several varieties were offered to it in exactly similar form. For example, the Poona rats are "bajri" eaters, the Madras rats chiefly rice eaters, and so on. The experiments were most carefully carried out on a very large scale and under conditions as natural as the limitation of such an experi. ment permit; the results were confirmed time and again and are beyond dispute. The addition of such substances as cheese, for which rats are popularly supposed to have a marked predilection, sugar, various essential oils, and numerous other substances were tried, with the result that none of the flavoured baits were as attractive as the plain dough baits. Even butter and other fats and oils detracted from the attractive value of the plain dough bait; such substances are commonly recommended as desirable ingredients of poison baits.

The bearing of such observations on the efficient prosecution of a rat campaign, be it by means of trap or poison, needs no elaboration.

A comprehensive knowledge of the habits of rats is likewise essential to the designing of "rat-proof " dwellings and buildings if such are to be kept rat-free. $R$. rattus is unable to junp higher than $2 \frac{1}{2} \mathrm{ft}$.; it is unable to circumvent a horizontal ledge of 9 in. provided this be smooth on the under surface; it cannot live on dry grain without a certain amount of water to drink; such points are all important. I am unable to quote similar facts about $R$. norvegicus; they could, however, easily be ascertained experimentally.

All the commonly recommended rat poisons, and several others, were subjected to investigation, with the result that none were found as efficient as barium carbonate, which is one of the very few poisons that the rat fails to detect. It is safe to handle, and in the amounts necessary for use it is not dangerous to children. It was found that 15 grains were necessary to kill a cat, 20 grains to kill a chicken, and that dogs could withstand a dose of 140 grains. Phosphorus poisons are relatively distasteful however offered.

In India poison baits are recommended to be made as follows:

One pound of barium carbonate is mixed thoroughly with three pounds of flour made from the grain which forms the stiple food of the human population of the locality in wh ch operations are to be carried out. The mixture can conveniently be made in an enamelled basin. Sufficie nt water is added to make the whole into a fairly firm pt ste. The resulting mass is sufficient for some 2,300 baits each containing 3 grains of barium carbonate. Clean hands and dishes are necessary to avoid the addition of extraneous taste and odour which might diminish the attractiveness of the baits.

Baits should be made fresh each day or at most every second day; a bard stale bait is very rarely eaten by a rat. The baits are distributed in groups of four in such parts of a bailding as are frequented by rats; this is best done in the evening. A record should be kept of the number of baits so distributed and the number taken. During poisoning operations special efforts should be made to keep all food usually available for rats covered up.
I make no reference to the use of bacterial viruses for the destruction of rats. I imagine such means of rat destruction have but a limited vogue at the present day. Quite apart from any possible dangers attending their use, experience of plague makes one seeptical of their effecting anything but a very temporary reduction in the rat population. No bacterial infection of which we have know. ledge is more readily communicable from rat to rat or more fatal to rats than is plagne. Plague has flourished among the rats of India for twenty-three years; nevertheless there were sufficient rats in India in 1917-18 to determine the fourth worst plague epidemic on record.

\section{HERPES ZOSTER OF THE GLOSSO- PHARYNGEAL NERVE.}

\author{
BY C. T. NEVE, M.B., B.S., F.R.C.So, \\ CROYDON.
}

The following case presents several points of interest bearing on the pathology of herpes:

On July 12th Miss M., aged 57, complained of sore throst, which she attributed to a long and cold motor drive two days previously. She was first seen on July 14th. She had that day vomited, was feeling ill, and complained of vague pains behind the left ear and in the back of the neck on the left side. The temperature was $100^{\circ}$, there was paralysis of the left facial nerve (periphersl type), the tongue was furred, especially on nerve peripheral type), the tongue was furred, especially on palate and fauces were reddened, the former presenting a palate and fauces were reddened, the former presenting a epithelium. One of these vesicles was just to the right of the mid-line. Taste was normal. The skin of the auricle was unaltered.

On July 17th the temperature had fallen to normal, and the tongue was nearly clean; vesicles were still present, though less marked. For two days she had noticed that she was deaf on the left side. The meatus and membrana tympani appeared on the left side. The meatus and membrana tympani appeared the acoumeter being heard at two inches only.

The facial paralysis was treated by the interrupted current, and on August lst there was slight though definite return of voluntary power in all the facial muscles. The hearing was much improved, though still a little dulled, acoumeter being now heard at twelve inches. The palate was now normal and the general health fair.

In brief the symptoms presented were: (1) fever and vomiting, (2) facial palsy of peripheral type, (3) an auditory nerve affection, (4) on the mucous surface supplied by the glosso-pharyngeal nerve an eruption resembling that of herpes zoster, (5) pain felt behind the ear and down the left side of the neck posteriorly.

Ramsay Hunt in $1907^{1}$ put forward the view that herpes auricularis, in which the eruption is limited to the tympanum, external auditory canal, and auricle, is due to herpetic inflammation (posterior poliomyelitis) of the geniculate ganglion. He describes four varieties:

(1) Herpes anricularis.

(2) Herpes auricularis with facial palsy.

(3) Herpes auricularis with facial palsy and hypoacousis.

(4) Herpes auricularis with facial palsy and Ménière's complex.

These complications sometimes occur in herpes facialis, occipitalis, and cervicalis, and he explains this fact upon the theory that while the inflammation may predominate in one ganglion, others near by may participate in a milder form, the zones here named being controlled by the Gasserian, geniculate, and cervical ganglia.

In the case here described there was facial palsy and hypoacousis, but not the herpes auricularis. In its place there was herpes of the palate. Was this due to herpetic inflammation of the ganglion of the glosso-pharyngeal nerve?

With regard to the possibility of this occurrence, Ramsay Hunt" says: "If the Gasserian and geniculate ganglia, by virtue of their unipolar type, belong to the series of ganglia liable to the inflammation of zona, the same would also be true of the ganglia of the glosso-pharyngeal nerve and of the vagus nerve. These ganglia are also regarded by histologists as belonging to the unipolar or spinal type, and therefore cannot be excluded from the realm of herpes zoster." Hunt does not describe any cases in which he has found evidence of involvement of the ninth nerve, though he describes one case of herpes auricularis in which stiffness of neck, frequent vomiting, and slow irregular pulse suggested that the vagus might be affected: Sequeira (Diseases of the Skin, 1919) mentions buccal 